\title{
Learning to deliver LGBT+ aged care: exploring and documenting best practices in professional and vocational education through the World Café method - CORRIGENDUM
}

Trish Hafford-Letchfield, Alfonso Pezzella, Sandra Connell, Mojca Urek, Anže Jurček, Agnes Higgins, Brian Keogh, Nina Van de Vaart, Irma Rabelink, George Robotham, Elisa Bus, Charlotte Buitenkamp and Sarah Lewis-Brooke

(First published online 28 April 2021)

DOI: https://doi.org/10.1017/S0144686X21000441, Published online by Cambridge University Press, 13th April 2021

Key words: LGBT+; ageing; education; health care; social care; best practices; World Café; co-production; BEING ME; European Union; corrigendum

This article was originally published with incorrect affiliations for authors Agnes Higgins and Brian Keogh, who are in fact affiliated with the School of Nursing and Midwifery, Trinity College Dublin, the University of Dublin, Ireland. The article has now been updated with the correct information.

\section{Reference}

Hafford-Letchfield T et al. (2021). Learning to deliver LGBT+ aged care: exploring and documenting best practices in professional and vocational education through the World Café method. Ageing \& Society 1-22. https://doi.org/10.1017/S0144686X21000441

Cite this article: Hafford-Letchfield $\mathrm{T}$ et al (2023). Learning to deliver LGBT+ aged care: exploring and documenting best practices in professional and vocational education through the World Café method CORRIGENDUM. Ageing \& Society 43, 249-249. https://doi.org/10.1017/S0144686X21000611

(C) The Author(s), 2021. Published by Cambridge University Press. This is an Open Access article, distributed under the terms of the Creative Commons Attribution licence (http://creativecommons.org/licenses/by/4.0/), which permits unrestricted re-use, distribution, and reproduction in any medium, provided the original work is properly cited. 